\title{
Stratified ontology, institutional pluralism and performance monitoring in Zambia's health sector
}

\begin{abstract}
Purpose

This paper investigates funding and performance monitoring practices in Zambia's health sector from an institutional and stratified ontology perspective. Such an approach was deemed appropriate in view of pluralistic institutional environments characterising most African economies that are also considered to be highly stratified.
\end{abstract}

\section{Design/methodology/approach}

Blended with insights from stratified ontology, the paper draws on institutional pluralism as a theoretical lens to understand the institutional structures, mechanisms, events and experiences encountered by actors operating at different levels of Zambia's health sector. The study adopted an interpretive approach that helped to investigate the multifaceted and subjective nature of social phenomena and practices being studied. Data were collected from both archival sources and interviews with key stakeholders operating within Zambia's health sector.

\section{Findings}

The study's findings indicate the high levels of stratification within Zambia's health sector as evidenced by the three sector levels that possessed different characteristics in terms of actor responses to donor influence. This study equally demonstrates the capacity of agents operating under highly fragmented institutional environments to engage in enabling and constraining responses depending on the understanding of their empirical world.

\section{Originality/value}

Through blending insights from stratified ontology with institutional pluralism, the study contributes to the literature by demonstrating the enabling and constraining reflexive capacity of agents to exercise choices under highly fragmented institutional environments while responding to multiple demands and expectations in order to sustain the co-existence of diverse stakeholders. Accordingly, the study advances thinking on the application of institutional theory to critical accounting research in line with recent ontological and epistemological shifts in institutional theory.

Key words: Donor funding, institutional pluralism, performance monitoring, stratified ontology, Zambia 


\section{Introduction}

This paper investigates funding and performance monitoring practices in Zambia's health sector from an institutional and stratified ontology perspective. Such an approach was deemed appropriate in view of pluralistic institutional environments existing in most African economies (including Zambia) that are also considered to be highly stratified (World Health Organisation, 2013; Yu, 2013; Wickramasinghe, 2015). The pluralistic nature of institutional environments in these economies is aggravated by the presence of donor and supranational institutions (such as the World Bank, United Nations, World Health Organisation,) who often have different institutional prescriptions from local stakeholders on funding and performance reporting (Rahaman et al, 2010; Phiri and Guven-Uslu, 2018). Such contradictions have the potential to compromise the quality of health service delivery in the absence of appropriate responses from actors operating at different levels of the health sector as attested by complaints from some government agencies in Zambia regarding the vertical application of donor-funded resources (Ministry of Health and World Bank, 2010).

In view of the stratified and pluralistic institutional environment within Zambia's health sector, the study draws on institutional pluralism and insights from stratified ontology to understand the challenges encountered by actors at the health facility level and how they responded to these challenges. Institutional pluralism refers to situations where institutional actors are confronted by multiple and often contradictory stakeholder logics, demands and expectations (Kraatz and Block, 2008; Yu, 2013). Institutionalisation in stratified environments brings more challenges for actors since they have to respond to more than one institutional perception and identity (Kraatz, 2009). Despite Ekeh (1975) subscribing to the notion of two publics (the civic and the primordial publics), Mbembe (2001, p. 104) argues that post-colonial Africa is characterised by chaotic multiple public spaces rather than just two, 'each having its own logic yet liable to be entangled with other logics when operating in certain contexts'. The parallel existence of these multiple public spaces comes with great implications of a dialectical nature. For instance, attaining legitimacy to important stakeholders is a critical component in pluralistic environments as this has the capacity to affect access to resources from influential stakeholders. Consequently, actors in pluralistic environments have to respond to competing stakeholder expectations at different institutional levels. Such situations challenge actors to skillfully produce integrative practices out of contentious processes (Kraatz, 2009; Pache and Santos, 2010; Yu, 2013).

On the other hand, stratified ontology considers actors' actions and institutional structures as two separate ontologically different but related levels of reality manifested at the real, actual, and empirical domains (Bhaskar, 1977). Both structures and actors' actions possess distinctive emergent properties, relative autonomy, a previous existence, and causal efficiency, and they are in constant interaction (Leca and Naccache, 2006). What happens in the domain of the real with its attached structures and causal powers has the capacity to generate events in the domain of the actual, which, in turn, is able to affect the experiences of actors in the empirical domain of reality. 
This stratification, coupled with pluralistic institutional environments, may present particular challenges for actors who have to ensure that while stakeholder expectations may not necessarily be reconcilable, they have to be fulfilled through integrative processes. This situation is true about Zambia's health sector where multiple supranational institutions including donor agencies exert considerable influence on the design, implementation and monitoring of healthcare programmes through their funding mechanisms.

The study aims to enhance our thinking on the application of institutional theory to critical accounting research (Modell, 2014) in terms of how actors operating at different levels of the health sector respond to competing needs in the course of healthcare funding and performance monitoring. When coupled with stratified ontology (Bhasker, 1977; Sayer, 1992; Mutiganda, 2013), institutional pluralism helps to improve our understanding of particular institutional characteristics in the real, actual and empirical domains of reality in the course of designing, implementing and monitoring healthcare services. This nuanced view helps to demonstrate how certain taken-for-granted aspects of healthcare at the national level influence the events at the regional and facility levels as they transpire into everyday experiences of agents at the facility level in the course of health service delivery (van Helden and Uddin, 2016). In view of the foregoing, the paper seeks to respond to the following questions:

RQ1: What operating characteristics of institutional pluralism are depicted within Zambia's stratified health sector?

RQ2: How do actors at different levels of the health sector respond to the influence and needs arising from stakeholders with different expectations in the course of funding and performance monitoring?

In order to respond to these questions, the paper draws on institutional pluralism as an ontological and epistemological dimension of institutional theory (Modell, 2014). Drawing on critical discourse analysis as a research method, the study's findings indicate that actors operating at the health facility level encountered diverse pressures from stakeholders at the regional and institutional levels who also included donor institutions. In order to ensure harmony between these stakeholders, facility level actors had to respond to these pressures in an enabling and integrated manner. The study, therefore, contributes to the literature by demonstrating the enabling and constraining reflexive capacity of agents to exercise choices under highly fragmented institutional environments while responding to multiple pressures in order to sustain the co-existence of diverse stakeholders. The rest of the paper is organised as follows: the next section presents a literature overview on healthcare funding and performance monitoring within African countries. Section 3 discusses the theoretical positioning of the study while section 4 presents a summary of Zambia's health sector. Section 5 explains the research design while findings are presented in section 6 . The paper closes with conclusions and reflections on theoretical and methodological reflections. 


\section{Healthcare funding and performance monitoring in African countries}

African countries portray unique characteristics within the healthcare funding and performance monitoring practices due to existing pluralistic institutional environments. Global supranational actors such as the World Bank (WB), the International Monetary Fund (IMF), and the World Health Organisation (WHO) heavily influence the healthcare systems of these countries since they prescribe and often dictate institutional structures and practices regarding funding and accounting systems. The influence of these institutions arises from the significant amount of resources invested into African countries' health systems. For example, Gautier and Riddle (2017) report that in 2008 external institutions provided more than 20\% of total health expenditure in nearly half of the 46 countries in the WHO African region. Following the signing of the United Nations' Millennium Development Goals and the subsequent Sustainable Development Goals, the African region alone received $36 \%$ of total global aid (more than any other part of the world). Statistical evidence also shows that over the first decade of the millennium, aid to Africa quadrupled from around US\$11 billion in 2005 to US\$44 billion in 2008 (Ejughemre, 2013). The funding provided by global institutions to Zambia's health sector increased from 34\% in 2004 to $53 \%$ in 2010, representing a 56\% increase ( $\mathrm{MoH}$ and World Bank, 2010). In other countries such as Malawi, donor funding consistently accounted for more than $40 \%$ of the total health expenditure between 2001 and 2010.

On the other hand, Burundi and Tanzania registered a significant increase in the relative importance of donor funding between 2005 and 2010 (World Health Organisation, 2013). Consequently, it may be argued that actors of these systems work in environments where multiple funding and performance monitoring systems coexist (Rahaman et al., 2010). Most of these funding and accounting prescriptions are received by government stakeholders at the policy level who have to convey these to regional and facility level stakeholders in form of clinicians and managers. Lower level stakeholders operating at the regional and facility level may have no knowledge of the existence of these mechanisms and have no choice but to receive these prescriptions for implementation as given by donor institutions. It seems reasonable to argue that donor institutions and government policy actors operate largely at the real domain of the health sector as they design and formulate funding mechanisms and strategies without the involvement of the implementers. Such mechanisms consequently lead to events at the regional level; leading to different experiences at the health facility level as clinicians and managers implement the funding and performance monitoring practices. Consequently, the political voice and power of governments in African countries may be limited due to the influence of external stakeholders (Gautier and Riddle, 2017).

There have been some critical concerns that not all the donor support targeted at improving healthcare delivery is reaching communities with the greatest need or being delivered in a manner that is proving effective (Ejughemre, 2013). In order to fulfill their institutional goals, donor institutions often identify optimal structures for channeling their finances to the healthcare system. 
Such funding is usually provided in the form of 'health care programmes' aimed at specific disease or disease groups (WHO, 2009) that are considered as top priorities by these institutions (Adugna, 2009). There is statistical evidence from both the Organisation for Economic Cooperation and Development and the International Development Association regarding the consistent upward trend in the total amount of donations into health systems in Africa from the late 1990's to late 2000's (De Renzio, 2006; Adugna, 2009). This type of donor arrangement has been particularly influential in funding HIV/AIDS programmes to Africa over the past two decades (Rahaman et al, 2010). While the HIV/AIDS expenditure has been on the rise relative to total donor funding, donor funding aimed at other parts of the system has stagnated during the same period (Shiffman et al., 2009). However, such 'vertical' funding mechanisms that bypass government structures may not always please African leaders since they are seen to ignore government policy and national health priorities (Phiri and Guven-Uslu, 2018). Governments of these countries accept these funds on the premise that donors subsidise the cost of running the health sector (Waddington, 2004) and provide the means for these countries to work towards their national health strategies and achieve their objectives. The acceptance of such funds by African governments requires the delicate action of balancing the expectations of donor institutions, national health policies and priorities and the needs of local communities and clinicians and managers running health facilities.

There is a common theme in the literature (e.g., Uddin and Tsamenyi, 2005; Tsamenyi et al, 2010; Neu et al., 2010; Rahaman et al, 2010) regarding the strong influence of supranational institutions on financial, governance and performance related processes in these countries (Rahaman et al, 2004; Rahaman et al, 2007). One area still lacking in these studies is the understanding of how these institutions enlist accounting technologies to propagate their favoured development policies and how local actors accommodate and deploy these prescriptions for effective results. A recent study of local and central government in Tanzania (Goddard et al., 2016) directed attention to various responses of actors from the public sector and Non-Governmental Organisations (NGOs). Phiri and Guven-Uslu (2018) equally report on how local actors within Zambia's health sector embraced diverse performance reporting systems to fulfill the information needs of both supranational institutions and local communities. However, these studies appear to ignore the intricate mechanisms triggered at the national level that in turn triggered events at the regional level to explain experiences and practices at the health facility level.

A notable weakness of existing literature is that most of these studies have been conducted at one particular organisation with limited attention paid to a multi-level analysis of institutional fields. In this paper, the institutional field of Zambia's health sector is analysed using a multilevel approach by collecting evidence from three different groups of actors (at the national policy planning, at the regional health offices and at the health facilities). Such an approach helped to bring to the fore the views and voices of actors employed by the ZHS in order to provide an inside-out perspective of the extant supranational structures and their influence on institutional actors at different domains. 


\section{Stratified ontology and institutional pluralism}

This section is broken down into two sub-sections in order to provide theoretical clarity. It begins by discussing the concept of stratified ontology as a precursor to the theoretical underpinning of institutional pluralism discussed later.

\subsection{Stratified ontology}

Stratified ontology assumes that reality is shaped by social, political, cultural, economic, and ethnic factors that become reified into a series of structures that are then taken as 'real'. Stratified ontology encompasses the empirical, the actual, and the real aspects of social reality as separate domains which are deemed to exist independently. According to Bhaskar (1977, p. 82),

$[\ldots]$ the domain of the empirical is constituted by our quite fallible human perceptions and experiences...the domain of the actual - constituted as it were by the events and actions that transpire moment-to-moment...which in turn are caused by the countless, often unseen or taken-for-granted mechanisms and conditions that form the constellation of the domain of the real...(emphasis added).

According to this view, the domain of the real lies under the domain of the actual that in turn lies under the domain of the empirical (figure 1). Scambler (2001, p. 35) explains the tripartite domains differently when he states that 'the world is not composed [...] merely of events (the actual) and experiences (the empirical) but also of underlying mechanisms (the real) that exist whether or not detected and govern and facilitate events.

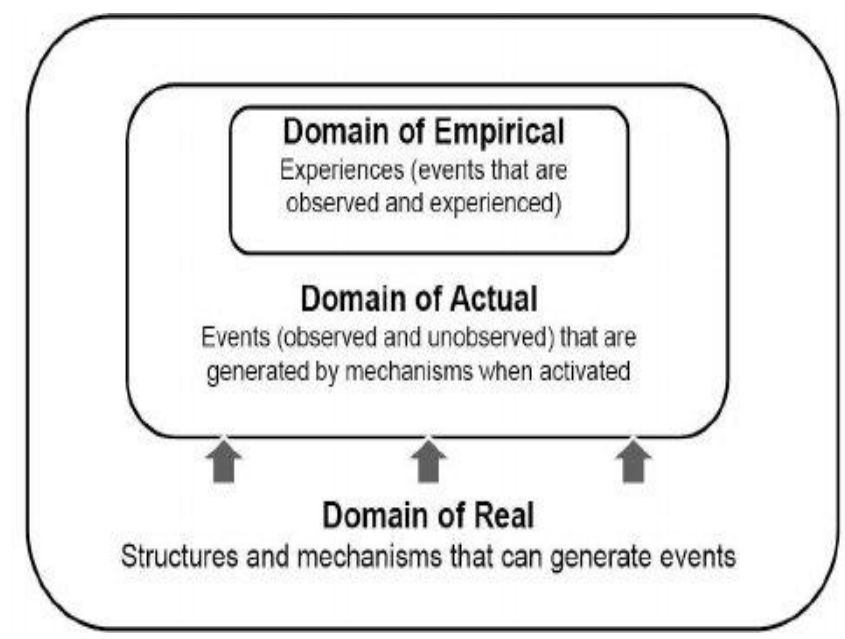

Figure 1: The three overlapping domains of reality

Source: Raduescu and Vessey (2009)

The domain of empirical is the domain of experienced events and involves the level of actors' sensations, impressions, and perceptions of reality. The domain of actual includes events, whether observed or not. 
Such events can happen independently of the experience and perception that actors may have of them. Events can happen and yet not be transferred into the domain of the empirical until human agency has identified correctly those events and transformed them into experience (Bhaskar, 1977; Sayer, 2000). On the other hand, the domain of real consists of the structures and causal powers that generate events independently of the idea that actors have of it. In other words, causal powers in the real domain can exist independently of empirical results (Leca and Naccache, 2006). In stratified ontology the objects and structures can be influenced by different mechanisms located in the real domain of reality, causing other different events to occur in the actual domain of reality.

Consequently, it may be argued that the occurrence of an event is not only dependent on the institutionalisation of the rules and routines underlying it but also on the activation of a mechanism in the real domain of reality, which is a necessary condition for that event to occur. Institutions have particular powers and liabilities that shape the ways institutional actors think and act in particular ways. It is therefore, appropriate to perceive institutions as being located in the real domain (Mutiganda, 2013) despite Leca and Naccache (2006) considering institutions as being located in the actual domain of reality. Actors operating in the actual domain of reality face different challenges and have different experiences from those that shape the empirical domain of reality. Accordingly, it may be argued that there is intra-institutional change that takes place between the actual and empirical domains. Intensive field studies are suitable and encouraged for stratified ontology because they allow for the understanding of how interactions between actors and their mechanisms lead to events that take place in the actual domain of reality and the effects of these events on the experiences of actors in the empirical domain of reality, which lead to different events in the continuous process of change (Sayer, 1992). The stratified institutional field under study is consistent with the assumptions of stratified ontology.

\subsection{Institutional pluralism}

Institutional pluralism, as an ontological and epistemological dimensional shift of institutional theory (Modell, 2014), refers to the situations faced by an organisation that operates within multiple institutional spheres (Kraatz and Block, 2008, p. 1). Actors operating in pluralistic environments cannot merely enact taken-for-granted institutional scripts but are compelled to exercise choice in their actions (Kraatz, 2009; Pache and Santos, 2010; Seo and Creed, 2002; Covaleski et al, 2013). Organisations operating in pluralistic environments are deemed to be multiply constituted since they have more than one institutional identity and more than one societal purpose (Kraatz, 2009). The African context offers a rich research field for operationalising institutional pluralism due to the pluralistic environments existing in these countries. Several studies conducted in these countries confirm the evidence of the significant influence of supranational institutions on accounting, financial management and performance measurement and management (PMM) practices through their funding activities (Rahaman et al, 2007; Rahaman et al, 2004; Uddin and Tsamenyi, 2005; Phiri and Guven-Uslu, 2018). 
A well-debated aspect of classical institutional theory is its limitations in explaining how and to what extent internal processes could remain decoupled from external pressures. The process of decoupling suggests that there is an active agency operating within the organisation and out of reach of institutional pressures. Such a conception of agency is inconsistent with the ontology of classical institutionalism (Kilfoyle and Richardson, 2011). Modell (2015) addresses this inconsistency in his suggestion for institutional accounting research to absorb some critical nature through more political engagement in analyses. Such an approach is deemed to be consistent with recent advances in critical realism. Modell (2015), therefore, proposes a 'stratified ontology' approach originally advanced by Bhashkar (1977) and further developed by Archer (1995) in the analysis of institutional processes within pluralistic environments. This ontology is seen to be particularly useful for understanding the role of agency in the institutionalisation processes through the study of the reflexive capacity of individuals and collectives. It is in this regard that the concept of stratified ontology has been blended with institutional pluralism to provide a useful analytical lens for the study of Zambia's pluralistic health sector.

\section{Structure of Zambia's health sector}

This section provides a summary of Zambia's public healthcare institutional structure in order to enhance matters related to sampling and data collection discussed in section 5 . The Ministry of Health (MoH) Headquarters, the executive body responsible for policy formulation and coordination, forms the apex of the healthcare system and is headed by the Minister of Health who is a political appointee of the President. The activities of the Ministry are monitored and overseen by the Parliamentary Committee on Health that only enjoys advisory powers. An external funding structure commonly referred to as 'cooperating partners' (donors) exists at this high level that influences the funding and design of health programmes. Intermediate structures in form of Regional Health Offices (PHOs) are responsible for providing a functional link between the Ministry headquarters and District Health Offices (DHOs). RHOs are also in charge of coordinating and supervising the implementation of health programmes within respective provinces. DHOs are responsible for coordinating primary healthcare at the district level.

On the service delivery side, Zambia runs a five-tier health service delivery system. Health posts and health centres are responsible for primary healthcare at the community level. District hospitals also provide primary care but at the district level. The provision of secondary care at the provincial level is the mandate of general hospitals while tertiary care at the national level is provided by central hospitals and teaching hospitals. Therefore, performance reports from all health posts, health centres and district hospitals are expected to be submitted to the DHOs who remit these to the RHOs for onward submission to the MoH headquarters. However, this reporting link is often defied by cooperating partners who fund some health programmes directly without following the institutional hierarchy; they also demand performance reports directly from health facilities directly funded by them rather than collect these from the $\mathrm{MoH}$ headquarters $(\mathrm{MoH}, 2011)$. 


\section{Research method}

The study adopted an interpretive approach that helped to investigate the multifaceted and subjective nature of social phenomena and practices being studied from an agency perspective (Lukka and Modell, 2010). A discourse analytical approach was used for making social sense of institutional and organisational practices (Alvesson and Karreman, 2000). Discourse was taken to refer to both text and talk as represented by written text and transcripts of spoken experiences of human actors (Fairclough, 1993). In operationalising the research design, the paper drew on critical discourse analysis (CDA) as a suitable investigative tool. Rather than focusing on textual linguistics, CDA has its focus on social problems and how economic and cultural dimensions influence power relations. CDA is also concerned with institutional structures and agency in terms of how relationships and levels of dominance affect institutional experiences and discourses (Titscher et al, 2000; Llewellyn and Northcott, 2005). Accordingly, CDA helped to understand tensions embedded within political and operational dimensions that characterise influence as reflected by institutional structures together with the responses of agents. It was an effective tool for investigating and analysing experiences and power relations and how this in turn influenced the responses of agents to multiple pressures (Jorgensen and Phillips, 2002).

The study relied on both archival text and primary accounts with respondents who possess sufficient knowledge and expertise on matters under investigation. This approach helped to understand not only extant structures of international donor organisations but also how the resource power of these elites influenced healthcare practices at the national, regional and health facility levels. Primary data were collected through semi-structured interviews with 33 respondents operating within Zambia's health sector. These respondents included five (5) legislators sitting on the Parliamentary Committee on Health and six (6) policy makers from the Ministry of Health $(\mathrm{MoH})$ headquarters (constituting institutional level respondents); ten (10) regional health office (RHO) officials that constituted regional level respondents; and twelve (12) healthcare professionals and managers representing facility level respondents. In line with stratified ontology, the study considered that institutional level, regional level, and facility level respondents were respectively linked to the real, actual and empirical domains of reality (Mutiganda, 2013) in respect of facility level actors. Consequently, structures and mechanisms emerging from the institutional level were regarded as causing different events to occur at the regional level, leading to different perceptions and experiences by actors operating at the health facility level. Respondents at each analytical level represented diverse expertise and trades including accountants, health economists, business administrators, nurses and medical doctors.

Conducted between 2013 and 2019, most of these interviews lasted between 45 minutes and an hour. All interviews were conducted in English, guided by a semi-structured interview protocol and digitally recorded. Audio recordings were later professionally transcribed and read through several times by the author to validate the transcript content. Primary interview accounts were complimented by and triangulated through documental evidence based on policy, planning, monitoring and review documents sourced from the $\mathrm{MoH}$ headquarters. 
The data analysis process entailed coding the data in view of recurring themes and discourses that addressed the study's research questions. In analysing transcripts and archival text, the study focused on quotes that reflected articulations of healthcare funding and performance monitoring discourses (Llewelyn and Northcott, 2005). Such an inductive approach also enabled the researcher to identify patterns of experiences, consistencies and contradictions, and linkages between these patterns in harmony with the theoretical framework.

\section{Findings}

Consistent with the theoretical framework, the sub-sections below present findings in relation to the pluralistic institutional environment that affects individual agents regarding how they respond to the influence of dominant stakeholders.

\subsection{The pluralistic institutional environment}

The institutional environment within the health sector portrays features of pluralism due to the multiplicity of stakeholders responsible for the funding, design and implementation of the country's health policy and strategy. Two institutions are evident within Zambia's health sector. One institution comprises donor organisations that are commonly referred to as cooperating partners (CPs). This institution is a major source of health funding in Zambia, contributing an average of $53 \%$ towards the health budget $(\mathrm{MoH}, 2009)$. These CPs feature in form of bilateral and multilateral donors that include UN agencies, the WB, the WHO, the Global Fund to fight Tuberculosis, AIDS and Malaria (GFTAM), the European Union and other philanthropic organisations like the Clinton and Gates Foundations. This type of funding is usually not channeled through established government structures but goes directly to healthcare organisations through NGOs and other contractors. The other institutional structure comprises government agencies where the Ministry of Finance provides the budget for operating expenditures directly to the $\mathrm{MoH}$ while CPs provide the budget for health programme expenditures through basket funds to the $\mathrm{MoH}(\mathrm{MoH}, 2011)$. These basket funds are provided in tandem with government's budgetary allocation structures and are managed and monitored closely within the $\mathrm{MoH}$ expenditure framework. Accordingly, a joint report by the MoH and World Bank (2010, p. 172) has stated the following in relation to donor funding practices:

[The] flow of funds from CPs depends on the type of funding. Basket funds and general budget support funds flow through GRZ [Government of the Republic of Zambia] systems. Sector budget support and earmarked funds flow directly to implementers [health facilities and NGOs]...

Much of the funding from the donor institution is disease-specific in nature and based on the priorities of individual donor organisations. Hence donor resource allocation structures have fragmented the institutional environment since these resources are not allocated via recommended government structures. 
Donor funding has further fragmented the institutional environment due to bypassing government structures and channeling resources directly to health service providers and NGOs that are not part of official government structures. Donor organisations have demonstrated their influence over the years through elevating the role of NGOs. The joint report by the MoH and World Bank (2010, p. 131) further states that:

The recent increase in disease-specific donor financing has increased the fragmentation. With large, vertical or disease-specific components targeting malaria, HIV/AIDS, TB and so on, donor funding has contributed to the fragmentation...National Health Accounts showed that donors have increasingly started to channel their funds through NGOs and other international agencies. Whereas the MoH transferred 63 percent of donor resources in 2003, the proportion dropped to 43 percent in 2005 and 29 percent in $2006 \ldots$

The $\mathrm{MoH}$ has reiterated government's concern with incompatible donor priorities and the fragmentation resulting from donor funding structures. The concern does not only arise from donors' emphasis on HIV/AIDS programmes but also due to donor resources that are applied without government's involvement. Archival evidence indicates reservations among government agencies regarding donor practices due to potential adverse effects of the fragmentation resulting from donor resource allocation structures. This practice is perceived to contradict government's priorities and the fulfilment of government's health goals. The MoH (2009, p. xiv) highlights the fragmentation caused by the donor institution:

The majority of HIVIAIDS health funds averaging at 41 per cent were managed by donors and international NGOs...This situation raises the issue of the sustainability and effectiveness of aid for HIV/AIDS given the fact that little resources are under the control of the $\mathrm{MoH}$ which has the stewardship role for the health of the population in Zambia...

The pluralistic nature of funding structures propagated by donors arises from the fact that each donor organisation may require different financial reporting and accountability templates and practices. The Chairperson of the Parliamentary Committee on Health, a former Cabinet Minister, relived his experiences of fragmented reporting structures perpetuated by donors:

There were instances where there would be multiple reporting systems by my staff. That was not the best utilisation of time in our country.

The effect of the fragmented institutional environment created by the donor institution is evident here. While fully aware of national health priorities that need to be addressed, institutional actors at the national level embrace donor funding structures as a way of conforming to donor influence despite the potential disruption of donor mechanisms on government's health policy. 


\subsection{External institutional influence at policy level}

Zambia's health policy and strategy are guided by key institutional values and aspirations as enshrined within the National Health Strategic Plan (NHSP), the Seventh National Development Plan (7NDP) and the Vision 2030 (V2030). While the purpose of the V2030 is to transform Zambia into a thriving and prosperous middle-income economy by the year 2030 , the $7 N D P$ is aimed at achieving sustained economic growth and poverty reduction. The $N H S P$, while forming part of the 7NDP, has been crafted with the vision oriented towards the attainment of health-related Sustainable Development Goals (SDGs) and other health priorities in a clean, caring and competent environment (MoH, 2011; Republic of Zambia, 2006, 2011). Archival evidence indicates the existence of a second and separate institutional mechanism propagated by donor organisations. These institutions are consulted in the course of formulating the country's health policy. International institutions are thus regarded as providing critical mechanisms of influence at the real domain of reality. However, most donor-funded programmes are perceived by local healthcare stakeholders to be implemented in a coercive manner. The Chairperson of the Parliamentary Committee on Health reiterated the influence of donor organisations on the country's health policy.

Many times in developing countries these guys [CPS] have come to say, 'We've got a pot of money for HIV and AIDS', the other one says, 'Malaria', and the other says, 'I'm concerned with diarrheal diseases so [here is] money for water and sanitation'. And they say, 'We are accountable to our governments for these funds, here is how the programme should be done'.

Further, the pluralistic nature of funding structures propagated by the donor institution is believed to have compromised government's health policy and strategy. A Principal Planner in charge of Budgeting at the $\mathrm{MoH}$ headquarters expressed his reservations with donors' funding mechanisms.

Vertical funding or parallel funding: this is a situation where money is given through certain programmes - it could be earmarked for T.B., HIV/AIDS or malaria...That's not the way it should be... But there are certain partners who prefer to fund like that due to their own different reasons.

In expressing his reservations with the influence of donor organisations, a Deputy Director of Monitoring and Evaluation from the $\mathrm{MoH}$ headquarters reiterated the influence of donor organisations within the health sector. Despite being considered as reputable institutions, the influence of such international organisations is perceived to be so disruptive that government ministries are often diverted from focusing on their set goals.

Most of the programmes that the sector implements draw their mandate from internationally recognised institutions like the WHO. That has been the case but at times there have been challenges where partner influence on certain activities causes country ministries not to focus on what they are supposed to do... 
Such donor influence has resulted into mechanisms and events that have affected institutional structures and activities of the health sector. This pressure entails that institutional actors have to respond either to reproduce donor structures and practices or to transform these prescriptions through integrative, adaptive and developmental approaches in order to conform to the needs of local communities.

\subsubsection{Actor responses to external influence at policy level}

Institutional actors have developed innovative ways of responding to donors' influence on the country's health policy and strategy depending on how they interpret the mechanisms emerging from donor organisations. One of such mechanisms is through integrating HIV/AIDS programmes favoured by donors with reproductive health programmes prioritised by government. The Chairperson of the Parliamentary Committee on Health explained:

There were projects specifically for HIV/AIDS until recently when we said, 'Look, we are not making much progress through this isolation approach. Why don't we integrate HIV/AIDS into sexual and reproductive health?' Money was in HIVIAIDS...But now there is a move that we also pay equal attention because the deaths from these [reproductive health diseases] are now surpassing those from HIV and malaria.

Another legislator reiterated that priority government goals and areas are those outlined in the NHSP as a key institutional document. This calls for the alignment of all donor funded programmes with government priorities and goals.

What is of crucial importance to the government is that there is a document which guides the sector to undertake its programmes - whether it's at national level, provincial level or at the health facility level. The National Health Strategic Plan spells out the activities that are supposed to be conducted in line with priority activities for the sector.

Institutional actors have also advocated for the adaptation of donor programmes and funding structures to ensure that these are implemented on mutual agreement with government and modified for local effectiveness. This entails that rather than government simply conforming to donors influence, input into the design of health programmes should also be provided by local agents. A Deputy Director of Monitoring and Evaluation contended that external programmes have to be adapted based on local needs in an attempt to make such programmes suitable for meeting local health expectations.

If they [donors] are undertaking a particular programme we have to use the agreed description of those programmes. But at the end of the day these programmes, even if they are coming from outside the country, have to be adapted to suit the country's situation.

Other agents have resorted to the negotiating table with donor organisations in an effort to harmonise government health goals and donor funding structures. 
Acknowledging the influence of donor organisations on government's health policy, a Chief Health Planner from the $\mathrm{MoH}$ headquarters narrated that government and donor organisations have developed joint annual review committees that are responsible for undertaking joint planning and programme reviews to ensure that the interests of both parties are represented in the design of health programmes.

Eventually when we have an action plan it is one that is jointly agreed upon. When a programme is implemented every year we have a joint annual review where partners and government come together to do a review of performance for the previous year.

Such joint structures and mechanisms demonstrate actions of an integrative and adaptive nature in an attempt to align government's health policy and strategy with donor priorities. What is prominent from these accounts, however, is the tendency by local institutional actors in taking a negotiated approach in their response to the pressure emerging from donor organisations. Rather than either transforming or reproducing donor mechanisms, agents have resorted to identifying strategic ways for adapting and balancing donor demands with the needs of local communities.

\subsection{External institutional influence at regional health offices}

It is considered that donor mechanisms and practices of bypassing government offices to create separate resource allocation structures contradict government goals and the intended impact of health programmes even at the RHO. The lack of integration of donor programmes into the mainstream health system creates further difficulties in assessing the impact of health programmes. A Senior Compliance Officer painted a gloomy image of the influence of donor organisations when his office was coerced into accepting donor funding that was inconsistent with the priorities of his office.

You find that when these guys [donors] are financing they always want to say, 'These monies can only be used in this and that; you can't use them in the other angle'. Then you find that those are not the areas where you really want financing. We've gone through that process; it is so common where you find that these guys bring in their conditions and they want you to spend the way they want. I must admit that sometimes it doesn't help.

One mechanism in which donor power has been demonstrated is through donors bypassing government structures to implement health programmes through NGOs in order to pursue their own interests. A Medical Officer working at a RHO explained.

Unfortunately, there have been some Cooperating Partners who have their own interest. There was a time when donors would deal directly with Non-Governmental Organisations; they would bypass the Ministry of Health and fund NGOs directly.

Such donor practices are perceived to prevent government agents from undertaking health programmes and activities that are consistent with the needs of local communities. 
This position was reiterated by the District Health Accountant who lamented over the rigid nature of donor funding structures to the extent that critical areas are often neglected.

When we are given money [by donors], we have guidelines on how we are supposed to spend that money...we've got activities that we are supposed to carry out. So each and every activity is given a certain percentage of that funding...we do not spend according to our wishes.

On the other hand, there were other actors who encountered contrary events. For instance, the process of developing healthcare standards was an area where donors remained distant. They left RHO agents to develop new healthcare standards based on their professional judgement. A Monitoring and Evaluation Specialist in charge of regulating nursing practice at the RHO echoed these sentiments and reiterated that donors had never imposed practices or healthcare standards on her office. Instead, donors provided financial and technical support that helped her organisation to achieve the set goals.

Cooperating Partners come to assist us with finances and technical advice. But the onus is on us because we have documents that we refer to. For nurses and midwives we have the International Council of Nurses document which we use. So we get the information from our sources and then we adapt them to our situation. We have never been imposed upon by donors... what we want is what we have!

Similar to standard setting, there was more room for local decisions to shape the education and curriculum needs within the health sector. For instance, the Education and Training Manager indicated that while donors finance many programmes including curriculum development and review, these projects are largely driven by the RHO. She dismissed the notion of donors imposing their ideas and stressed that programmes are developed and implemented in a collaborative manner.

I wouldn't say they impose. They come up with their ideas and it's us, as a Council in collaboration with the Ministry of Health, who take it according to our own understanding. Cooperating Partners help us in activities that are in the action plans, some of which are wholly financed by them. For example, if we have to review the curriculum, there are partners who are interested in certain portions of the curriculum so they come in with their finances to help.

As the above contradicting scenarios attest, donors had varied means of influencing RHO activities, both directly and indirectly. It was evident that the nature of influence was different between setting of clinical standards, education plans and financial requirements. For setting up of healthcare standards, there was a tendency by donors to leave this process to health professionals and to trust the judgment of these actors. The tendency was similar in the design of education programmes that were left to RHO managers. 
However, requirements and expectations in accounting practices were more rigid and centrally defined contrary to the expectations of accountants. Accordingly, various agents at this domain reacted differently as explained below.

\subsubsection{Actor responses to external influence at regional offices}

In view of the influence from donors explained above, a District Health Accountant narrated how resource structures were adapted and transformed from initial donor prescriptions in an attempt to fulfill critical health needs.

Though we are guided [on how to use donor money], there are certain times whereby we could divert a bit in terms of certain things that were not planned for but they are important and they have come up, so sometimes we do spend on such.

Another form of response has been achieved through integrating different donor funding streams. The concept of 'basket funding' has been introduced by government agencies in an attempt to pool and integrate donor resources for ease of expenditure and performance monitoring. A Medical Officer explained the nature of this integrative mechanism.

There was so much duplication of programmes; so much wastage of funds...So we developed this concept of 'basket of funding' so that every donor puts their money into one basket and then the Ministry sieves through and people apply to that basket so that there is no duplication; everyone knows what everybody is doing.

In other instances, memoranda of understanding have been signed to ensure that the views and interests of internal stakeholders are embraced in the implementation of donor-funded health programmes. The exercise of such response depicts an elevated level of influence by local agents in shaping institutional and organisational practices. This point was explained by a Senior Human Resource Officer.

Because you have to sit down and talk to these people to say 'this is what we need'. And if they are trying to impose, the people that are in charge of that particular area are supposed to advise to say we actually don't need this. When people come out and say 'we don't need this', then it shouldn't go ahead. For some programmes to take place there should be a memorandum of understanding that should be signed...

Accordingly, the response to donor mechanisms by actors operating at regional offices is largely reflected in terms of integrative practices in the case of the Medical Officer and more of developmental reflexes for the Accountant and the Senior Human Resource Officer.

\subsection{External institutional influence at health facility level}

Donor pressure at this level reflects the influence of donor structures and mechanisms on health service delivery processes and practices at the health facility level. Field evidence indicates that donor prescriptions, often given from a distance, lack the efficacy for meeting organisational goals. 
A Medical Officer working within a health facility reflected on donor influence that led to the implementation of health programmes without the involvement of local stakeholders.

Unfortunately, there have been some Cooperating Partners who will ask you to go along a certain path specifically from their own perspective. You find that some health programmes have been designed outside the country and we are supposed to follow them. In a way those programmes fail because they are not developed by the community inside the country.

Such donor power entails that local agents are coerced into embracing health service practices that are incompatible with the needs of the communities they serve. A Monitoring and Evaluation Specialist working within a health facility reported on incidents where his attempts to contract a traditional health provider in a remote area to run a reproductive health promotion programme led to the termination of funding by the donor.

They stipulate exactly how they want you to do things; if you do not follow what they want then you will not be funded. And if they come to do an evaluation, part of the evaluation is to observe. [If] They observe that you are using a traditional health provider then they will just cut you off from funding.

Some actors justified embracing donor mechanisms and practices as a way of receiving international modern practices. The belief is that local healthcare practices may still be lagging behind compared to those propagated by international organisations. A Sister in Charge at a health facility explained:

Basically most of the programmes could be from abroad but if we gauge ourselves against what may be prevailing in the Western world, I think we are still behind in terms of equipment and modernising a lot of issues. What we are doing is probably suitable for our environment but it's not very adequate either. So we have a bit of Western and our own...

In addition to the external design of such programmes, the influence of donor organisations is equally witnessed in the form of dictated operational practices of health service delivery. This influence often entails that healthcare providers have to abandon their own work plans in order to conform to donor demands. A Finance Manager working in a donor-funded facility elaborated the nature of donor influence on her work.

Cooperating Partners have got influence. At times we even lose focus of our own plans because they demand things that are not in our work plans; so we end up doing things that are outside our work plans.

Other health facility managers have embarked on identifying and embracing new cost effective approaches for dealing with imposed donor practices. One such mechanism is the home-based care programme. 
A Health Programmes Manager narrated how budgetary deficits and restrictive expenditure guidelines led to the introduction of home-based care programmes by her organisation. She contended that this initiative has helped to decongest the poorly-funded and ill-equipped health facilities throughout the country.

The home-based care programme in the country was started in one of our facilities and it was rolled out...And if you look at the programme, it even helps to alleviate the congestion in hospitals because a lot of chronically ill people are looked after in their own homes. That meant reducing on the number of cases admitted in hospitals with chronic conditions.

The influence of donor organisations extends to imposing templates of performance and financial reporting. These mechanisms are intended to ensure that financial reports reflect all amounts budgeted and actually spent on specific activities. This point was elaborated by a Senior Hospital Accountant who lamented that these expenditure guidelines leave little room for discretionary decision making on his part.

From the way these monies are supposed to be spent, there is a program that we call Financial and Administrative Management System (FAMS). There is a report that we need to submit every quarter and this report goes to the donors and there is a certain format that they want us to spend and that is the format that they send us. When they send [the money], they normally tell us that these monies are supposed to be spent in the following programmes.

Some donor practices and programmes are propagated on the rationale that they emerge from reputable organisations and institutions. Accordingly, government agents are expected to adopt, reproduce and further develop such donor practices. A Health Programmes Manager narrated how her organisation has adopted donor programmes on the belief that these international organisations conduct research to test the suitability of such programmes.

And I think this is how they influence because they do a lot of studies; [they] test some strategies to see how effective they are and share with countries and organisations to see if they can help in improving the healthcare in the country. WHO, for instance, comes up with a lot of strategies, they influence countries to say 'this is a proven initiative and it can help improve the status of the health service in the country'.

The above experiences depict the diverse nature of donor pressure exerted within health facilities. However, this influence has demonstrated the potential to disrupt health facility actors from engaging in practices that prioritise the needs of local communities.

\subsubsection{Actor responses to external influence at the health facility level}

Actors at the health facility level have developed innovative ways of responding to donor influence; these responses range from passive integration of donor practices to active adaptation of these practices and at times developing modified or new practices. 
These responses have enabled actors to become more consistent with the needs of their local communities. While presenting a picture of conformance to donor demands, some actors have identified skillful ways of bypassing donor funding and expenditure restrictions in the course of health service delivery. A Senior Hospital Accountant explained:

There is a small area of manoeuvring whereby you would explain to your boss [saying], 'Please this budget line needs these unforeseen competing events'. At a hospital like ours, [if] a patient comes and we tell him that we don't have certain drugs, people will not accept that. So there are areas whereby at least you come and say, 'Sir with your permission may I get this [donor] money, when I get my grant I will reimburse'.

Further to such ploys, other agents have explored alternative ways of passively defying the rigid donor funding structures and practices. One hospital has embarked on income generating mechanisms to supplement government grants through the provision of premium services to the community. These internally generated resources provide flexibility and autonomy to hospital managers to spend in ways that reflect their identified priorities, contrary to the rigidity embedded within donor funding structures. This point was elaborated by a Finance Manager.

We have what we call PAMSCO [Partnership in Medical Scheme with Communities]. The purpose of introducing PAMSCO is to supplement local income in form of government grants.

This response reflects innovative actions by organisational actors in terms of mobilising funding. Evidence equally indicates that some faith-based health facilities have developed checklists that are used as a form of agreement with donor organisations before funding is accepted. Such organisations ensure that donors consent to their ethical and moral code for resource application before resources are disbursed. A Senior Human Resource Officer explained.

Some partners nowadays come with money and say, 'We have this program, are you able to handle it'? We sit down and discuss. If it fits in our work plan, that's when we accept the funding. If you look at this organisation, it is a health and Christian organisation; so both aspects [health and Christian] are looked into.

The above accounts demonstrate that some accountants and managers are not satisfied with simply conforming to coercive pressure from donor organisations at the expense of meeting the health needs of local communities. To the contrary, they have developed innovative tools to ensure that while they receive financial support from influential donor organisations, they equally fulfil their organisations' goals and the health priorities of their communities in line with their professional values. 


\section{Discussion of findings}

This paper aimed at addressing the way selected actors of the ZHS respond to global health policies and their associated funding and performance monitoring practices. Institutional pluralism blended with stratified ontology was utilised to analyse multiple institutional pressures and the responses of agents to these pressures at three levels of the ZHS. The study focused on the conforming and contrasting responses of actors to the influence of external institutional structures. The sub-sections below discuss the study's findings.

\subsection{Actors' responses to external pressure at policy level}

Maintaining a balance between the influence of global health institutions and national health programmes was a notorious task for almost all interviewees. There were two major types of pressures from global institutions at the policy level. The first one was the injection of funds directly to healthcare providers, bypassing the $\mathrm{MoH}$. The pressure was associated with a distinct set of accounting technologies in terms of reporting and PMM practices. This created a contradiction between the national accounting practices and accounting practices introduced by global funding institutions resulting in a fragmented and highly pluralistic environment in terms of funding and PMM practices. Agents perceived this divide as highly constraining in relation to their work as there was not much they could do to make or initiate any change; hence their reactions were more of adaptive and communicative in nature. The other pressure from supranational institutions was through their direct financial and strategic involvement in the management of the national healthcare system. The agents responded to this in various ways. In response to the multiplicity of strategic aims and objectives, some agents showed negotiation and political skills as evidence of enabling responses in order to establish and maintain a dialogue with relevant institutions so that some level of harmony could be maintained between these two separate sets of priorities.

On the other hand, in response to the multiplicity of performance targets and reporting requirements, agents responded in a more constraining manner as these prescriptions and processes were essential features in securing the continuation of funding from donor institutions. This meant that the sustainability of health services was dependent on following these rules and practices. Therefore, agency in response to accounting technologies at the policy level was limited in terms of its enabling properties. Agency at that level was more about adaptation and harmonisation in conforming ways with a purpose to improve communication between multiple stakeholders. These findings demonstrate the importance of having a closer collaboration, establishing of joint working parties, and sharing of concerns and expectations at policy level between national and international actors. This position is essential in order to provide some potential in bringing together these multiple sets of pressures with the goal of generating jointly-agreed sets of priorities and goals. Such mechanisms are seen here to be necessary for ensuring the co-existence of multiple stakeholders in a pluralistic institutional environment. 


\subsection{Actors' responses to external pressure at regional offices}

At the level of regional offices the evidence was slightly different. Regional offices represented the intermediary level between policy stakeholders and health facilities. Actors in these offices were of varied professional backgrounds including medical, managerial and accounting professionals. It was evident from the analysed data that there was some discomfort and unease in the comments of interviewees in relation to donor funding mechanisms bypassing their offices and going directly to healthcare organisations in local communities through NGOs. On the other hand, there were some areas such as training and setting of healthcare standards where they felt more comfortable and encouraged to devise their own approaches. Theoretically, the findings indicate that donor pressure at regional offices was indirect but highly influential in its constraining characteristics; not leaving much space for agents to exercise choice in the areas of accounting technologies and PMM practices. In contrast to this, particularly in areas not directly related to accounting, agents were expected and encouraged by donor organisations to exercise their choice, make decisions, design and implement changes. The above findings imply that the role and responsibilities of regional offices were acknowledged and that donor organisations would engage with these offices in a more harmonious and collaborative way in order to address the challenges that these offices face for both funding and performance monitoring practices. Donors adopted a more flexible approach towards certain activities and this enabled agents to be more active and to take responsibility in designing certain aspects of the healthcare service. Accordingly, it appears that this collaborative approach minimised the fragmentation observed at the policy level. In the absence of such collaborative mechanisms, the fragmentation could endure and become more difficult to overcome as the reliance of the health sector on donors appears to be consistently increasing.

\subsection{Actors' responses to external pressure at health facilities}

At the level health facility level, the influence of donor institutions was direct and highly influential in compromising organisational plans and priorities. For instance, it was concerning to some interviewees that certain disease areas were over-funded by donors while others did not receive sufficient funds despite being identified as priority areas by the government. In case of any deviation from external prescriptions on organisational practices, the implications for the organisation were immediate in terms of termination of international funding with detrimental consequences to the health facility. Therefore, the influence of international institutions at the health facility level was highly dominant on actors, reinforcing the constraining properties of external power and strengthening the institutional structures in these areas. Nonetheless, it was evident that certain agents found themselves in situations of "what works" to find pragmatic solutions to problems originating from the health needs of local populations or any organisational priorities. There were several examples of enabling properties of agency in these instances including generating new income streams, manoeuvring of expenditures between agreed and alternative lines, as well as contracting out of new providers who had their own sets of ethical and other conditions for donor organisations to agree. 
The responses of these agents were of receptive, adaptive and creative nature in these instances, opening new possibilities for the organisation outside the externally designed structures of international institutions. This finding implies that promoting the enabling capacity of agents would be an essential feature in considering and responding to the needs of local communities while fulfilling the expectations of donor institutions. It is through this capacity that societal needs could be sensed and responses devised in an efficient manner. Theoretically, it was evident that institutional structures and mechanisms continued to influence the events and actions of agents at the RHO and health facility levels; albeit in a less direct and more fragmented manner. For instance, abandoning action plans due to donor influence left some agents in situations where they were bound to make non-optimal decisions incapable of meeting the health needs of local communities. Consequently, there were instances of choice of action by agents in both constraining and enabling ways.

\section{Concluding remarks}

Consistent with stratified ontology and institutional pluralism, the above findings provide the possibility to observe the three stratification levels of reality as they possessed different characteristics at three levels of analysis. At the policy level, the donor institution was observed to be highly influential and dominant, thereby limiting the enabling capacity of agents. This institution triggered funding and PMM structures and mechanisms that constrained the capacity of actors at the policy level from reacting in a more adaptive and communicative manner. However, these structures and mechanisms triggered events that had different characteristics at the level of regional offices where donor institutional mechanisms on funding and PMM could largely be ignored. These events are perceived in terms of healthcare programmes, funding and PMM prescriptions; which consequently triggered agent choices and actions that were more adaptive and less constraining on their part. In areas where there was no direct influence from donors, there was the opportunity for agents to respond in more enabling ways of a developmental nature.

At the health facility level, it was evident that despite the continued presence of donor mechanisms and prescriptions of funding and PMM, there was apparently more room for agents to respond in enabling ways as they had to meet the immediate health needs of local populations within the financial and operational limits of their organisations. Accordingly, these agents appeared to be in a continuous search for alternative ways to meet the needs of diverse stakeholders and enable them to co-exist in the pluralistic environment (Kraatz and Block 2008; Pache and Santos, 2010; Yu, 2013). This study, therefore, contributes to the literature by demonstrating the enabling and constraining reflexive capacity of agents to exercise choices under highly fragmented institutional environments while responding to multiple pressures in these environments in order to sustain the co-existence of diverse stakeholders (Mutiganda, 2013; Modell, 2014, 2015). More importantly, these responses demonstrated different characteristics at different levels of the ZHS despite some actors being consulted by donor institutions (e.g., at the policy level) while others experienced donor prescriptions of a coerced nature (e.g., at the health facility level). 
This understanding has policy implications since it does not only reveal the differences in stakeholder expectations of funding and PMM within the health sector's policy but, more importantly, demonstrates the importance of harmonising these expectations with the goal of co-existence among different stakeholders (Modell, 2014). The study has shown how donor structures and mechanisms at the institutional level triggered events of diverse nature at the RHO, which ultimately triggered different perceptions and experiences at the health facility level; consequently calling for different responses and actions from actors. Through blending the concept of stratified ontology with institutional pluralism, the study has demonstrated how actors operating in stratified institutional environments are able to navigate the inherent institutional intricacies using reflexive agency through making choices based on their own empirical world. Further studies on this capacity of agents could provide beneficial results for the advancement of institutional theory. One such avenue could be through engaging actors from donor institutions in order to capture their thinking and voices on the choices they make in the course of funding and setting performance standards. This is particularly important since the current study only provided the views of actors operating within government and donor-funded health facilities. Consequently, the absence of donor voices in this study is acknowledged as a key weakness in the design of the study that future studies could improve on. 


\section{References}

Adugna, A. (2009), 'How much of official development assistance is earmarked?' CFP Working Paper Series No. 2, New York: World Bank.

Alvesson, M. and Karreman, D. (2000), 'Varieties of discourse: On the study of organisations through discourse analysis', Human Relation, Vol. 53 No. 9, pp. 1125 - 1149.

Archer, M.S. (1995), 'Realist social theory: the morphogenetic approach', Cambridge University Press, Cambridge.

Bhaskar, R. (1977), 'A realist theory of science', London, Verso.

Covaleski, M.A., Dirsmith, M.W., Weiss, J.M. (2013), 'The social construction, challenge and transformation of a budgetary regime: The endogenisation of welfare regulation by institutional entrepreneurs', Accounting, Organizations and Society, Vol. 38 No. 5, pp. 333364.

De Renzio, P. (2006), 'Aid, budgets and accountability: a survey article', Development Policy Review, Vol. 24 No. 6, pp. 627 - 645.

Ejughemre, U.J. (2013), 'Donor support for community health financing: Options and opportunities for Sub-Saharan African communities', American Journal of Public Health Research, Vol. 1 No. 6, pp. 129 -134.

Ekeh, P.P. (1975), 'Colonialism and the two publics in Africa: a theoretical statement', Comparative Studies in Society and History, Vol. 17 No. 1, pp. 91-112.

Fairclough, N. (1993), 'Critical discourse analysis and the marketization of public discourse: The Universities', Discourse and Society, Vol. 4 No. 2, pp. 133-168.

Gautier, L., and Ridde, V. (2017), 'Health financing policies in Sub-Saharan Africa: Government ownership or donors' influence? A scoping review of policymaking processes', Global Health Research Policy, Vol. 2 No. 23, pp. 1 - 17, https://doi.org/10.1186/s41256017-0043-x.

Goddard, A; Assad, M; Issa, S; Malagila, J; T A Mkasiwa (2016) 'The two publics and institutional theory- A study of public sector accounting in Tanzania', Critical Perspectives on Accounting, Vol 40, pp 8-25.

Jorgensen, M. and Phillips, L.J. (2002), 'Discourse analysis as theory and method', London, Sage Publications.

Kilfoyle, E. and Richardson, A.J. 2011. 'Agency and structure in budgeting: Thesis, antithesis and synthesis'. Critical Perspectives on Accounting, Vol. 22 No. 2: pp. 183-199. 
Kraatz, M. S. (2009). 'Leadership as institutional work: A bridge to the other side'. In T. B. Lawrence, R. Suddaby, \& B. Leca (Eds.), Institutional work: actors and agency in institutional studies of organizations, Cambridge: Cambridge University Press.

Kraatz, M. S., and Block, E. S. (2008). 'Organizational implications of institutional pluralism'. In R. Greenwood, C. Oliver, K. Sahlin-Andersson, \& R. Suddaby (Eds.), The Sage handbook of organizational institutionalism. Los Angeles: SAGE Publications.

Leca, B. and Naccache, P. (2006), 'A critical realist approach to institutional entrepreneurship', Organisation, Vol. 13 No. 5, pp. $627-651$.

Llewellyn, S. and Northcott, D. (2005), 'The Average Hospital', Accounting, Organisations and Society, Vol. 30 No. 6, pp. $555-583$.

Lukka, K. and Modell, S. (2010), 'Validation in interpretive management accounting research', Accounting, Organisations and Society, Vol. 35 No. 4, pp. 462-477.

Mbembe, A. (2001), 'On the Post-colony', University of California Press, Berkeley, CA.

Ministry of Health (2009), 'Zambia National Health Accounts 2003 to 2006 - Final Report', Lusaka, Ministry of Health.

Ministry of Health (2011), 'National Health Strategic Plan 2011 - 2015', Ministry of Health, Lusaka.

Ministry of Health and World Bank (2010), 'Country Health Status Report', Lusaka, Ministry of Health and World Bank African Region Human Development.

Modell, S. (2014), "The societal relevance of management accounting: an introduction to the special issue", Accounting and Business Research, Vol. 44 No. 2, pp. 83-103.

Modell, S (2015) Making institutional accounting research critical: dead end or new beginning? Accounting, Auditing and Accountability, Vol. 28 No. 5, pp.773-808

Mutiganda, J.C. (2013), 'Budgetary governance and accountability in public sector organisations: An institutional and critical realism approach', Critical Perspectives on Accounting, Vol. 24 No. 7-8, pp. 518-531.

Neu, D., Rahaman, A.S., Everett, J., Akindayomi, A. (2010), 'The sign value of accounting: IMF structural adjustment programs and African banking reform', Critical Perspectives on Accounting, Vol. 21 No. 5, pp. 402-419.

Pache, A. C., and Santos, F. (2010), 'When worlds collide: The internal dynamics of organisational responses to conflicting institutional demands', Academy of Management Review, Vol. 35 No. 3, pp. 455-476. 
Phiri, J. and Guven-Uslu, P. (2018) 'Institutional pluralism, two publics theory and performance reporting practices in Zambia's health sector', Journal of Accounting in Emerging Economies, Vol. 8, No. 1, pp.141-162

Raduescu, C. and Vessey, I. (2009), Methodology in critical realist research: The mediating role of domain specific theory, Proceedings of the 15th Americas Conference on Information Systems, AMCIS 2009, San Francisco, California, USA, August 6-9.

Rahaman, A.S., Lawrence, S. and Roper, J. (2004), 'Social and environmental reporting at the VRA: institutionalised legitimacy or legitimation crisis?" Critical Perspectives on Accounting, Vol. 15 No. 1, pp. 35-56.

Rahaman, A.S., Everett, J., and Neu, D. (2007), 'Accounting and the move to privatize water services in Africa', Accounting, Auditing \& Accountability Journal, Vol. 20 No. 5, pp. 63770.

Rahaman, A., Neu, D. and Everett, J. (2010), 'Accounting for social-purpose alliances: confronting the HIV/AIDS pandemic in Africa', Contemporary Accounting Research, Vol. 27 No. 4, pp. 1093-1129.

Republic of Zambia (2006), 'Vision 2030: A Prosperous Middle-income Nation by 2030', Lusaka, Republic of Zambia.

Republic of Zambia (2011), 'Sixth National Development Plan 2011 - 2015: Sustained Economic Growth and Poverty Reduction', Lusaka, Republic of Zambia.

Scambler, (2001), 'Critical realism, sociology and health inequities: social class as a generative mechanism and its media of enactment', Journal of Critical Realism, Vol. 4 No 1, pp. 35-42.

Sayer R.A. (1992), 'Method in social science: a realist approach', London: Routledge.

Sayer R.A. (2000), 'Realism and social science', London: Sage Publications Ltd.

Seo, M., Creed, W.E.D., (2002), 'Institutional contradictions, praxis, and institutional change: a dialectical perspective', Academy of Management Review, Vol. 27 No. 2, pp. 222-247.

Shiffman, J., Berlan, D., Hafner, T. (2009), 'Has Aid for AIDS raised all health funding boats'? Journal of Acquired Immune Deficiency Syndrome, Vol. 52, Supplement 1, pp. 45 48.

Titscher, S., Meyer, M., Wodak, R., Vetter, E. (2000), 'Methods of text and discourse analysis', London, Sage.

Tsamenyi, M., Onumah, J., Tetteh-Kumah, E. (2010), 'Post-privatization performance and organizational changes: case studies from Ghana', Critical Perspectives on Accounting, Vol. 21 No. 5, pp. 428-42. 
Uddin, S. and Tsamenyi, M. (2005), 'Public sector reforms and the public interest: a case study of accounting control changes and performance monitoring in a Ghanaian state-owned enterprise', Accounting, Auditing \& Accountability Journal, Vol. 18 No. 5, pp. 648 - 674.

van Helden, J and Uddin, S (2016) 'Public sector management accounting in emerging economies: A literature review’, Critical Perspectives on Accounting, Vol 401, pp 34-62.

Waddington, C. (2004), 'Does earmarked donor funding make it more or less likely that developing countries will allocate their resources towards programmes that yield the greatest health benefits?' Bulletin of the World Health Organisation, Vol. 82 No. 9, pp. 703 - 708.

Wickramasinghe, D. (2015), 'Getting management accounting off the ground: post-colonial neoliberalism in healthcare budgets', Accounting and Business Research, Vol. 45 No.3, pp. 323-355.

World Health Organisation (2009), WHO Country Cooperation Strategy 2008-2013, WHO Regional Office for Africa, Brazaville.

World Health Organisation (2013), 'State of Financing in the African Region', World Health Organisation, Regional Office for Africa, Johannesburg.

$\mathrm{Yu}, \mathrm{K}-\mathrm{H}$ (2013), 'Institutionalisation in the context of institutional pluralism; politics as a generative process', Organisation Studies, Vol. 34 No.1, pp. 105-131. 